\title{
Relationship between patient-perceived quality of nurse caring attitudes and behaviours and quality of life of haemodialysis patients in Switzerland
}

Philippe Delmas*1 ${ }^{* 1}$ Matteo Antonini ${ }^{1}$, Tanja Bellier-Teichmann ${ }^{1}$, Evelyne Boillat ${ }^{2}$, Vanessa Brandalesi ${ }^{1}$, Louise O'reilly $^{3}$, Chantal Cara ${ }^{3}$, Sylvain Brousseau ${ }^{4}$, Delphine Roulet-Schwab ${ }^{1}$, Isabelle Ledoux ${ }^{5}$, Jérôme Pasquier ${ }^{6}$

${ }^{1}$ La Source, School of Nursing, HES-SO, University of Applied Sciences Western, Switzerland

${ }^{2}$ Geneva School of Health Sciences, HES-SO, University of Applied Sciences Western, Switzerland

${ }^{3}$ Université de Montréal, Montréal, Canada

${ }^{4}$ Université du Québec en Outaouais, Gatineau, Canada

${ }^{5}$ Université de Sherbrooke, Sherbrooke, Canada

${ }^{6}$ Institute of Social and Preventive Medicine, Lausanne University Hospital, Lausanne, Switzerland

Received: August 4, 2020

Accepted: October 9, 2020

Online Published: October 23, 2020

DOI: $10.5430 / \mathrm{cns} . v 9 \mathrm{n} 1 \mathrm{p} 1$

URL: https://doi.org/10.5430/cns.v9n1p1

\begin{abstract}
Background: Chronic kidney disease (CKD) is a fast-growing cause of morbidity and mortality worldwide. Patients suffering from CKD almost always develop end-stage renal disease (ESRD) that is often treated with haemodialysis (HD). In this context, the quality of the nurse-patient relationship (NPR) plays a major role in supporting the quality of life (QoL) of HD patients. This study examined the relationship between quality of nurse behaviours and attitudes as perceived by HD patients and QoL of these patients.

Methods: The study used a cross-sectional correlational design. The sample consisted of 140 patients recruited in 10 HD units in French-speaking Switzerland. The Caring Nurse-Patient Interaction Scale (CNPI-70) was used to assess the NPR, and the French version of the WHOQOL-Bref was used to evaluate different dimensions of QoL. Random-intercept linear regressions adjusted for sociodemographic characteristics were used to study the relationship between patient-perceived quality of nurse caring attitudes and behaviours and patient QoL.

Results: Patients reported a high frequency of caring attitudes and behaviours from their attending nurses, except relative to the dimension of spirituality. All the dimensions of patient QoL were positively influenced by the caring factor composing the CNPI-70. In particular, nurse attention to patient dignity when providing support for basic human needs seemed to be a major factor in patient QoL.

Conclusions: Quality of NPR is essential to improving patient QoL. Interventions need to be developed to support quality of NPR.
\end{abstract}

Key Words: Quality of life, Nurse-patient relationship, Haemodialysis patient, Watson's Theory of Human Caring

\footnotetext{
${ }^{*}$ Correspondence: Philippe Delmas; Email: p.delmas@ecolelasource.ch; Address: La Source, School of Nursing, HES-SO, University of Applied Sciences Western, Switzerland. 


\section{INTRODUCTION}

As a result of a long historical process, chronic illnesses became the first cause of death in Western countries. ${ }^{[1,2]}$ One of these - chronic kidney disease (CKD) - has been on a steady rise, notably as a consequence of other chronic diseases, such as diabetes and hypertension. CKD ranked 19th on the list of causes of the total number of global deaths in 2010 (annual death rate of 16.3 per 100,000) and is considered a major public health issue. ${ }^{[3]}$ In Switzerland alone, an estimated 350,000 people live with the condition, and, of these, 30,000 suffer from a severe form of the disease. Moreover, patients with CKD inevitably develop end-stage renal disease (ESRD), necessitating renal replacement therapy, the most common being haemodialysis. ${ }^{[42]}$ As pointed out by Chantrel, Lassalle, Couchoud, and Frimat, ${ }^{[5]}$ the transition to ESRD, particularly if it involves haemodialysis (HD), marks a radical change in the organisation of patient care. Prior to $\mathrm{HD}$, patient care consists primarily of dietary recommendations, medical interventions, and periodic monitoring. These interventions are carried out by an informal team made up of the patient's family physician and a nephrologist and leave ample room for patient autonomy. Once HD is initiated, however, patient care is managed almost exclusively by a multidisciplinary team working in the field of nephrology and implies greater involvement on the part of both the patient and healthcare professionals. ${ }^{[5,6]}$ Thus, patients on HD experience a number of disruptions in their daily life because they are required to undergo heavy medical treatment that normally entails three weekly sessions of 4 to 6 hours. ${ }^{[7,8]}$ Moreover, HD patients must continue to follow a strict diet low in salt, phosphorus, potassium, and fluid ${ }^{[4]}$ and must adhere to strict medical treatment. In this regard, some authors ${ }^{[9,10]}$ have underscored that, on top of having to bear the presence of severe symptoms,,${ }^{[7,11]} \mathrm{HD}$ patients suffer from psychological distress for various reasons, including the heavy limitations that treatment imposes, changes in body perception, economic difficulties, and uncertainty about their future. It has been observed that, because of all these problems, HD patients present high levels of anxiety and depression and that this has a heavy impact on their quality of life (QoL) ${ }^{[12]}$ which is a key indicator of their survival in the short term. ${ }^{[13]}$

According to some authors, ${ }^{[14,15]}$ nurses play a major role in making patients feel safe, in promoting their psychological wellbeing, and in helping them cope with their chronic illness. The ability of nurses to create a high-quality nurse-patient relationship (NPR), based on active listening and empathy, is a key factor supporting HD patient QoL. For Bennett, ${ }^{[16]}$ HD nurses must meet numerous challenges in the course of their work, such as maintaining a high level of competence in the technical and relational aspects of care to practise a holistic, person-centred nursing approach. In this regard, nurse caring practice, which is expressed through the quality of the human relationship established between nurse and cared-for person, quality of nurse presence, and touch, is an essential ingredient in the development of a person-centred approach that takes account of the patient's needs, values, and expectations.

The NPR in nursing care has been the topic of much discussion in the literature. ${ }^{[8,17-21]}$ In particular, according to Watson, ${ }^{[20,21]}$ nursing care is the ability to help people giving meaning to their existence, suffering, and lack of harmony through a process called the "transpersonal caring relationship". ${ }^{[22]}$ In Watson's theory, ${ }^{[20,22]}$ the transpersonal caring relationship allows nurses to achieve a deeper person-toperson connection in order to promote patients' wellbeing, healing, harmony, and empowerment. Nurses are required to ground their practice in a system of humanistic values that influence their attitudes and, in turn, guide their behaviours. According to Cara, ${ }^{[23]}$ these attitudes are expressed through authentic presence, compassion, active listening, understanding, support, reciprocity, and collaboration, and require a true commitment on the part of nurses for humanistic nursing practice. Desmond et al. ${ }^{[24]}$ stressed that the caring relationship played a central role in how patients viewed holistic health and Swanson ${ }^{[18,19]}$ showed in two literary meta-analyses how a caring relationship is beneficial not only to nurses and patients (self-esteem, QoL, length of hospital stay) but also to healthcare systems (costs). By contrast, patients exposed to uncaring attitudes and behaviours feel humiliated, frightened, helpless, and vulnerable states that can contribute to lengthening physical healing times. ${ }^{[18,19]}$ These results are also supported by Wei, Fazzone, Sitzman, and $\operatorname{Hardin}^{[25]}$ in a recent literature review of intervention studies based on Watson's Theory of Human Caring.

Consequently, the link between the patient-perceived quality of NPR and patient QoL seems crucial. Despite a growing body of literature in this regard, empirical evidence in support of this link remains almost non-existent, where the Swiss context is concerned. Moreover, the psychological mechanism linking Watson's approach to incremental improvement of patient QoL remains essentially unexplored. Against this background, we undertook a study to measure and describe patient perceptions of caring, patient QoL, and the relationship between the two in the context of HD units in French-speaking Switzerland.

\section{METHODS}

\subsection{Study design}

A cross-sectional correlational design ${ }^{[26]}$ was used to describe ten dimensions of caring attitudes and behaviours, 
and, successively, to investigate the links between patient perceptions of caring and patient QoL.

\subsection{Participants and setting}

A convenience sample of HD patients was recruited in 10 HD centres in the French-speaking part of Switzerland (Delémont, Geneva, Lausanne, Martigny, Monthey, Morges, Payerne, Porrentruy, Sierre, Sion, Yverdon-les-Bains) during a routine weekday HD session. To participate in the study, patients were required to meet the following inclusion criteria: 1) age 18 years or older; 2) under active treatment for at least six months, and 3) able to read and understand French. The questionnaires took about 30 minutes on average to complete and were collected at the end of the HD session. Overall, 202 patients met the inclusion criteria and agreed to participate in the study. Of these, 140 (69.3\%) completed the questionnaires. The main causes of withdrawal were a change in health status (10.4\%), death (7.4\%), and transplant (4.5\%).

\subsection{Measures}

\subsubsection{Sociodemographic data and clinical information}

The following sociodemographic data were collected from patients: age, sex, marriage status, occupational situation, children, and income. We also collected data on tobacco and alcohol use, duration of $\mathrm{HD}$, and presence of comorbid conditions. Clinical values were collected from hospital records, including specific biological data and a marker of $\mathrm{HD}$ adequacy $(\mathrm{kt} / \mathrm{v})$. This questionnaire was already used in a previous study on the same population, ${ }^{[7,8]}$ and no difficulties where identified.

\subsubsection{Caring relationship}

The Caring Nurse-Patient Interaction Scale (CNPI-70 ${ }^{[27,28]}$ ) was developed to assess nurse caring factors as described by Watson ${ }^{[21,22,29,30]}$ and to facilitate research on the relationship between caring and patient outcomes. The instrument comprises ten subscales, one for each caring factor, with a variable number of items. The items are rated on a five-point Likert scale ranging from "almost never" (1) to "always" (5), with higher ratings indicating more positive attitudes and behaviours in support of caring nurse-patient interactions. Cronbach's alphas for the subscales ranged from .73 to .91, and Pearson's correlation coefficients between the ten subscales ranged from .53 to $.89,^{[27]}$ suggesting overall good internal consistency. The scale has been used with different populations, notably nurses, ${ }^{[7,8,24,31,32]}$ patients, ${ }^{[7,8,24]}$ and nursing students. ${ }^{[31,32]}$ The instrument has shown good acceptability with HD patients. ${ }^{[7]}$

\subsubsection{Quality of life}

QoL was assessed with the French version of the WHOQOLBREF, ${ }^{[33]}$ an abridged version of the 100-item World Health
Organization Quality of Life instrument. The short version comprises 26 items, two of which serve to explore overall patient QoL and general health. The other 24 items fall under four domains: physical health (seven items), psychological state (six items), social relationships (three items), and environmental conditions (eight items). All of these items are rated on a five-point scale ranging from 1 to 5 , with higher ratings indicating better QoL. Then, the raw ratings were normalized on the 0-100 scale. The WHOQOL-BREF questionnaire has been shown to possess good discriminant and content validity, as well as good test-retest reliability and high internal consistency. ${ }^{[34]}$ The French translation was validated ${ }^{[33]}$ on French-speaking patients with neuromuscular disorders and has been proven to possess satisfactory psychometric properties (Cronbach's $\alpha$ above .65 for each dimension and good acceptability by the population with less than 5\% of non-responses). Moreover, this instrument was already successfully used in studies involving HD patients. ${ }^{[7,8]}$

\subsection{Data analysis}

First, numeric variables were described using means, standard deviations, medians, and interquartile ranges (IQR), while categorical variables were described using frequency tables and percentages. Second, random intercept linear regression models were used to examine the link between the ten dimensions of the CNPI-70 and patient QoL. The use of a random intercept regression model was necessary because, as participants were nested in HD units, measures referring to patients from the same HD unit could not be considered fully independent observations. The inclusion of control variables was determined empirically. Random intercept linear regression models and Kendall's correlation coefficients were used to determine whether any sociodemographic or health characteristic was related to patient QoL and patient, caring perceptions.

Given that these analyses were ancillary to our primary goal and merely explorative of possible relationships within our sample, a Bonferroni correction for multiple comparisons was applied to p-values to avoid type I errors. In all the analyses, we applied a frequentist approach, and p-value equal to or less than .05 was used as a threshold to evaluate the significance level of every result. All of the statistical analyses were run on the R Studio (version 1.2.5042) application. ${ }^{[35]}$

\subsection{Missing data}

For both the ten dimensions of the CNPI-70 and the four included in the WHOQOL-BREF, participants needed to answer at least $80 \%$ of the items relating to a dimension to obtain a valid rating for that dimension. Otherwise, the rating was considered missing and excluded from the analyses. Because of the scantiness of the literature regarding the factors 
that influence the perception of caring as measured with the CNPI-70, no data imputation was considered safe.

\subsection{Ethical consideration}

HD patients received a document explaining the purpose of the study and the procedures used to ensure anonymity. To this end, participants would be assigned a code. Patients had the right to withdraw from the research without consequence for their treatment Patient were afforded plenty of time to carefully consider their decision. Those who agreed to take part in the study were asked to sign a consent form that was then forwarded to the researchers. This study obtained an ethics certificate by the Human Research Ethics Review Board of the Canton of Vaud (CER-VD no2017-00946).

Table 1. Patients' characteristics of study patients

\begin{tabular}{|c|c|c|c|}
\hline \multirow{2}{*}{ Sociodemographic, clinical and biological characteristics } & \multicolumn{3}{|c|}{ Study group $(N=140)$} \\
\hline & Median (IQR) & $n$ & $\%$ \\
\hline Age (years) & $72(17)$ & & \\
\hline \multicolumn{4}{|l|}{ Sex } \\
\hline - Female & & 57 & 40.7 \\
\hline - Male & & 83 & 59.3 \\
\hline \multicolumn{4}{|l|}{ Marital status } \\
\hline - Single & & 19 & 13.6 \\
\hline - Married & & 74 & 52.9 \\
\hline - Separated & & 26 & 18.6 \\
\hline • Widowed & & 21 & 15.0 \\
\hline With an occupation & & 21 & 15.0 \\
\hline With children & & 100 & 71.4 \\
\hline Months on haemodialysis & $38.5(49.2)$ & & \\
\hline \multicolumn{4}{|l|}{ Tobacco use } \\
\hline - Smoker & & 20 & 14.3 \\
\hline • Non-smoker & & 120 & 85.7 \\
\hline On transplant waiting list (4 missing values) & & 56 & 40.0 \\
\hline Heart failure & & 34 & 24.3 \\
\hline Hypertension & & 67 & 47.9 \\
\hline Cardiac arrhythmia & & 34 & 24.3 \\
\hline Diabetes & & 38 & 27.1 \\
\hline Peripheral vascular disease & & 16 & 11.4 \\
\hline Chronic respiratory insufficiency & & 14 & 10.0 \\
\hline Tumour & & 20 & 14.3 \\
\hline Hepatitis & & 2 & 1.4 \\
\hline Amputation & & 18 & 12.9 \\
\hline Hemiplegia & & 3 & 2.1 \\
\hline Albumin $(\mathrm{g} / \mathrm{dL}, \min -\max : 3.5-5.0)^{*}$ & $3.9(0.4)$ & & \\
\hline Haemoglobin (g/dL, min-max: $12-16)^{*}$ & $11.1(1.4)$ & & \\
\hline Phosphate (mg/dL, min-max: $3.5-5.5)^{*}$ & $5.2(1.9)$ & & \\
\hline Calcium (mg/dL, min-max: $8.4-9.5)^{*}$ & $9.2(0.8)$ & & \\
\hline Parathyroid hormone (pg/mL, min-max: $150-300)^{*}{ }^{(1 \text { missing value })}$ & $166(216.9)$ & & \\
\hline $\mathrm{kt} / \mathrm{v}(\min -\max : 0.94-2.29)^{*}{ }_{(1 \text { missing value })}$ & $1.72(0.3)$ & & \\
\hline
\end{tabular}

Note. "According to $\mathrm{KDIGO}^{[36]}$ 


\section{Results}

\subsection{Sample characteristics}

From January to May 2018, 140 HD patients completed the questionnaire. The sociodemographic characteristics of these patients are shown in Table 1. Most participants were male $(59.3 \%)$. The mean age was 69.0 years $(S D=12.7)$. Almost three quarters had children (71.4\%), and just over half were married $(52.9 \%)$. Only a small minority had a professional activity (15\%), and the vast majority were nonsmokers $(85.7 \%)$. On average, they had been receiving HD for 62.5 months $(S D=78.3$ ), and $40 \%$ were on the transplant waiting list. As for medical history, $47.9 \%$ of the patients suffered from hypertension, almost $27.1 \%$ from diabetes, $24.3 \%$ from heart arrhythmia, and $24.3 \%$ from heart failure. A minority of patients were amputated $(12.9 \%)$ or suffered from hemiplegia $(2.1 \%)$. Mean clinical values all fell within non-problematic bounds.

\subsection{Patient perceptions of caring}

Table 2 presents the patient mean ratings of all 140 participants for the ten dimensions of the NPR measured by the CNPI-70. Patients rated all dimensions above 3, except Spirituality. Most dimensions were even rated above 4, notably F1-Humanism, F2-Hope, F4-Helping Relationship, F5-Expression of Emotions, F7-Teaching, F8-Environment, and F9-Needs. These findings suggested that HD patients perceived a high frequency of caring attitudes and behaviours from their attending nurses, similar to what was observed by Delmas et al. ${ }^{[8]}$ in a similar population of HD patients in French-speaking Switzerland. No sociodemographic or health factor appeared to be related to patient QoL, except patient sex: Men rated F9-Needs significantly lower than women $\operatorname{did}(\beta=-.25$; Bonferroni $p=.024)$.

\subsection{Patient QoL}

As shown in Table 3, the HD patients in our sample perceived a moderate to good QoL with mean ratings ranging from 3.35 (General health situation) to 4.50 (Environmental QoL) on a scale of 1 to 5 . These results are similar to or higher than those reported by Delmas et al. in a comparable population of Swiss HD patients. No sociodemographic or health factor appeared related to patient QoL, except for phosphate level, which was negatively correlated with the social relationships dimension $(\beta=-.02$; Bonferroni $p=.026)$.

Table 2. Patient perceptions of caring as assessed with the Caring Nurse-Patient Interaction Scale (CNPI-70)

\begin{tabular}{lcc}
\hline \multirow{2}{*}{ Dimensions } & \multicolumn{2}{c}{ Study group $(\boldsymbol{N}=\mathbf{1 4 0})$} \\
\cline { 2 - 3 } & Mean & $(\boldsymbol{S D})$ \\
\hline F1-Humanism & 4.49 & 0.55 \\
F2-Hope & 4.19 & 1.15 \\
F3-Sensitivity & 3.75 & 1.20 \\
F4-Helping Relationship & 4.42 & 0.74 \\
F5-Expression of Emotions & 4.07 & 1.10 \\
F6-Problem Solving & 3.42 & 1.35 \\
F7-Teaching & 4.31 & 0.92 \\
F8-Environment & 4.64 & 0.52 \\
F9-Needs & 4.68 & 0.44 \\
F10-Spirituality & 2.48 & 1.55 \\
\hline
\end{tabular}

Table 3. Patient quality of life as assessed with the WHOQOL-BREF

\begin{tabular}{lcccc}
\hline & Mean & SD & Mean (on a scale of 0-100) & SD (on a scale of 0-100) \\
\hline Physical health & 3.49 & 0.85 & 62.37 & 21.15 \\
Psychological health & 4.13 & 0.57 & 78.24 & 14.34 \\
Social relationships & 4.33 & 0.79 & 83.26 & 19.82 \\
Environmental QoL & 4.50 & 0.51 & 87.49 & 12.87 \\
General health situation & 3.35 & 1.08 & 58.75 & 27.00 \\
General QoL & 3.65 & 0.95 & 66.25 & 23.75 \\
\hline
\end{tabular}

\subsection{Relationship between patient perceptions of caring and patient QoL}

Kendall's correlation coefficients were calculated in a preliminary analysis to explore the association between each caring factor and each QoL dimension. Generally speaking, caring factors were moderately correlated with one another, as expected from a theoretical point of view. In addition, F1-Humanism and F4-Helping Relationship were correlated with two QoL dimensions: Social Relationships (respectively, $\tau=.24$, Bonferroni $p=.001$ and $\tau=.26$, Bonferroni $p=.004$ ) and Environmental QoL (respectively, $\tau=.26$,

Published by Sciedu Press
Bonferroni $p=.001$ and $\tau=.18$, Bonferroni $p=.035$ ), F7Teaching was correlated with General health situation $(\tau=$ .21 , Bonferroni $p=.028)$, and F9-Needs with General QoL $(\tau=.21$, Bonferroni $p=.026$ ). Given these results, some caring factors were entered as control variables in the random intercept regression models, as described in Table 4. In contrast, no sociodemographic or health variables were associated with either patient perceptions of caring or QoL. Consequently, none of these variables were entered into the models as control variables. 
Table 4. Relationship between patient perception of caring and quality of life

\begin{tabular}{|c|c|c|c|c|c|c|}
\hline & General QoL & General health & Physical QoL & Psychological QoL & Social relationships & Environmental QoL \\
\hline F1-Humanism & .187 & .139 & .193 & .021 & .239 & $.246^{*}$ \\
\hline Intercept & 2.827 & 2.732 & 2.629 & 4.029 & 2.700 & 2.801 \\
\hline Controls & none & none & none & none & Factor F4 & Factor F4 \\
\hline$N$ (individuals) & 137 & 137 & 135 & 133 & 111 & 134 \\
\hline Random intercept variance & .213 & .082 & .007 & .003 & .132 & .002 \\
\hline$N$ (groups) & 11 & 11 & 11 & 11 & 11 & 11 \\
\hline F2-Hope & -.056 & .109 & .083 & .039 & $.140^{*}$ & $.094 *$ \\
\hline Intercept & 1.514 & 2.459 & 3.136 & 3.965 & 3.749 & 4.107 \\
\hline Controls & Factor F9 & Factor F7 & none & none & none & none \\
\hline $\mathrm{N}$ (individuals) & 123 & 112 & 127 & 126 & 107 & 127 \\
\hline Random intercept variance & .225 & .007 & .005 & .003 & .119 & .003 \\
\hline $\mathrm{N}$ (groups) & 11 & 11 & 11 & 11 & 11 & 11 \\
\hline F3-Sensitivity & .013 & $.201^{*}$ & .070 & .066 & $.129 *$ & .056 \\
\hline Intercept & 1.929 & 2.658 & 3.272 & 3.897 & 3.942 & 4.336 \\
\hline Controls & Factor F9 & Factor F7 & none & none & none & none \\
\hline Random intercept variance & .220 & .008 & .005 & .003 & .005 & .005 \\
\hline$N$ (groups) & 11 & 11 & 11 & 11 & 11 & 11 \\
\hline F4-Helping Relationship & .064 & .108 & $.203^{*}$ & .008 & .126 & $.135 *$ \\
\hline Intercept & 3.378 & 2.870 & 2.593 & 4.083 & 2.700 & 2.801 \\
\hline Controls & none & none & none & none & Factor F1 & Factor F1 \\
\hline$N$ (individuals) & 135 & 135 & 133 & 131 & 111 & 134 \\
\hline Random intercept variance & .242 & .136 & .008 & .003 & .132 & .002 \\
\hline$N$ (groups) & 11 & 11 & 11 & 11 & 11 & 11 \\
\hline F5-Expression of Emotions & -.130 & .014 & .089 & .055 & .076 & .057 \\
\hline Intercept & 2.181 & 2.544 & 3.045 & 3.828 & 3.976 & 4.252 \\
\hline Controls & Factor F7 & Factor F9 & none & none & none & none \\
\hline$N$ (individuals) & 103 & 93 & 106 & 104 & 92 & 107 \\
\hline Random intercept variance & .217 & .009 & .006 & .004 & .151 & .004 \\
\hline$N$ (groups) & 11 & 11 & 11 & 11 & 11 & 11 \\
\hline F6-Problem Solving & -.049 & .139 & .067 & $.120^{*}$ & .064 & .047 \\
\hline$N$ (individuals) & 111 & 100 & 112 & 112 & 93 & 113 \\
\hline Random intercept variance & .252 & .006 & .006 & .004 & .181 & .003 \\
\hline$N$ (groups) & 11 & 11 & 11 & 11 & 11 & 11 \\
\hline F7-Teaching & .027 & .133 & .035 & .116 & .011 & .088 \\
\hline Intercept & 1.746 & 2.826 & 3.341 & 3.614 & 4.274 & 4.121 \\
\hline Controls & Factor F7 & none & none & none & none & none \\
\hline$N$ (individuals) & 112 & 115 & 113 & 111 & 96 & 113 \\
\hline Random intercept variance & .147 & .008 & .021 & .003 & .170 & .003 \\
\hline$N$ (groups) & 11 & 11 & 11 & 11 & 11 & 11 \\
\hline F8-Environment & .150 & .489 & .183 & .167 & .165 & $.257 *$ \\
\hline Intercept & 1.739 & 1.380 & 2.642 & 3.389 & 3.609 & 3.324 \\
\hline Controls & Factor F7 & Factor F9 & none & none & none & none \\
\hline$N$ (individuals) & 120 & 108 & 121 & 119 & 101 & 122 \\
\hline Random intercept variance & .223 & .006 & .005 & .004 & .169 & .002 \\
\hline$N$ (groups) & 11 & 11 & 11 & 11 & 11 & 11 \\
\hline F9-Needs & $.395^{*}$ & .330 & .283 & $.265^{*}$ & $.340 *$ & $.316^{*}$ \\
\hline Intercept & 1.837 & 1.509 & 2.187 & 2.885 & 2.790 & 3.028 \\
\hline Controls & none & Factor F9 & none & none & none & none \\
\hline$N$ (individuals) & 130 & 112 & 128 & 127 & 106 & 129 \\
\hline Random intercept variance & .213 & .007 & .005 & .003 & .167 & .002 \\
\hline$N$ (groups) & 11 & 11 & 11 & 11 & 11 & 11 \\
\hline F10-Spirituality & .020 & -.001 & -.030 & .047 & .058 & .002 \\
\hline Intercept & 3.700 & 3.409 & 3.625 & 4.161 & 4.184 & 4.552 \\
\hline Controls & none & none & none & none & none & none \\
\hline$N$ (individuals) & 86 & 86 & 85 & 85 & 67 & 85 \\
\hline Random intercept variance & .283 & .010 & .008 & .003 & .154 & .003 \\
\hline$N$ (groups) & 11 & 11 & 11 & 11 & 11 & 11 \\
\hline
\end{tabular}


The relationships between caring factors and patient QoL were modelled using random-intercept logistic regression (see Table 4). The results of these analyses showed a positive relationship between certain caring factors and patient QoL. General QoL appeared to be influenced by F9-Needs ( $\beta=.395, p=.026)$, and General health situation by F3Sensitivity $(\beta=.201, p=.032)$. Where Physical health is concerned, a significant positive relationship emerged only with F4-Helping Relationship ( $\beta=.203, p=.043$ ), while Psychological health appeared to be influenced by both F6Problem Solving $(\beta=.120, p=.003)$ and F9-Needs $(\beta=$ $.265, p=.020)$. Similarly, F2-Hope, F3-Sensitivity, and F9-Needs had a positive influence on Social relationships (respectively, $\beta=.140, p=.037 ; \beta=.129, p=.029$; and $\beta=$ $.340, p=.043)$. Finally, the Environmental QoL appeared to be the most affected by variations in caring levels associated with F1-Humanism ( $\beta=.246, p=.004)$, F2-Hope $(\beta=.094$, $p=.018)$, F4-Helping Relationship $(\beta=.135, p<.001)$, F8-Environment $(\beta=.257, p=.003)$, and F9-Needs $(\beta=$ $.316, p=.003)$.

\section{Discussion}

NPR can be considered a bridge between the patient and the healthcare system, which is why humanistic attitudes and behaviours are key to delivering optimal care. ${ }^{[37]}$ Research has shown that the NPR has a profound impact on patient satisfaction, especially in HD settings, where treatment involves prolonged (about four hours per session) and repeated (three times a week) interaction between patients and nurses. ${ }^{[8,16,38-41]}$ Our data have shown that, overall, patients perceived medium to high levels of caring, with seven out of ten dimensions rated three or higher on a scale of 1 to 5. These ratings are in line with previous observations in similar contexts. ${ }^{[8,41]}$ According to Watson, ${ }^{[20,21]}$ the ten caring factors describe an NPR where nurses can show compassion, respect, kindness, and impartiality, regardless of the patient's culture, beliefs, or orientations. Consequently, the higher the rating, the more patients perceive that nurses see them as people and not merely carriers of disease, support their efforts, adopt a teaching style focused on problem-solving, and are respectful of their intimacy and needs. Moreover, and most importantly, nurses can instil and support patients' hope in their future and the development of their global health condition.

The only exception in this pattern was F10-Spirituality, which received only moderate ratings. This factor reflects patient perceptions of nurses' ability to support their spiritual life and their existential quest. Understanding why nurses appear less effective in this task, relative to others, needs further investigation. Nevertheless, an analysis of the context may

Published by Sciedu Press afford important clues. Both Watson's theory of caring ${ }^{[20,21]}$ and Cosette's EIIP-70 instrument ${ }^{[27,28]}$ were originally developed in a North American context where spirituality is lived differently from how it is in Switzerland. In recent decades, Western public debate has shifted towards identity politics ${ }^{[42]}$ where people's beliefs and group membership play a central role. While religion is a main axis of division in the North American debate, it remains marginal in Switzerland and is limited essentially to the conflict between conservative parties and Islam. ${ }^{[43]}$ Religion, and non-traditional spirituality, to an even greater extent, remain largely a private matter in Switzerland. Swiss nurses and patients may be culturally uncomfortable discussing such topics explicitly and may adopt different strategies to deal with the spirituality dimension. Consequently, Swiss patients may not be inclined to address the subject with nurses and may not even need professional support in this regard.

Regarding patient QoL, a complex pattern emerged. Analysing patient QoL dimension by dimension, we observed that physical health pulled down what would otherwise be high patient assessments. Both general health situation and physical health were given only moderate ratings, about $60 \%$ of the maximum, whereas the other dimensions were given very high ratings closer to and even in excess of $80 \%$ of the maximum. The fact that patient assessments of their general QoL were much closer to their ratings for the physical health dimension than for any other suggests that physical health is the driving force behind HD patient QoL. Congruent with what we know of HD patients, their chronic health condition and the severe restrictions imposed by the HD treatment may push these patients to focus, sometimes excessively, on their physical health at the expense of all other aspects of their life.

Consequently, an NPR centred on humanistic values may be beneficial to help patients reframe their perspectives and focus on the positive elements of their life. Our findings support this theoretical framework as they evidence an overall positive relationship between patient perception of nurse caring attitudes and patient QoL. Patient assessments of the physical dimension of their QoL improve in the presence of a trusting-helping relationship (F4) between nurse and patient. HD nurses are the main actors in HD treatment and play a key role in advising HD patients on the daily management of their health condition. Establishing a relationship based on mutual trust and help promotes patient adherence to treatment and diet, ${ }^{[44]}$ which in turn contributes to improving their physical condition. As for patient perceptions of psychological QoL, a problem-solving approach (F6) to nursing and assistance with basic human needs (F9) appear to be the most relevant factors. Given the constraints of their condition, HD patients 
may be subject to high levels of psychological distress. ${ }^{[45]}$ If nurses can effectively solve patients' problems and assist them in maintaining their dignity while receiving assistance with their basic human needs, part of this psychological distress may be relieved, and their QoL may improve as a result. The social dimension of QoL was positively affected by F2 and F3 when these were rated high. These two factors coherently describe the basic principles of the NPR according to the caring theory, that is, authentic presence and sensitivity to self and others. The social dimension was also influenced by F9, the factor regarding assistance with basic human needs. This result underscores even more markedly how this factor is critical to the NPR in the context of HD treatment and how it promotes patient QoL over time. Finally, environmental QoL was positively affected by five caring factors: F1, F2, F4, F8, and F9. This shows that how people assess their environment is determined not only by the objective conditions of the structures and spaces that they live in but also by their subjective perception of these structures and spaces. This perception seems to be influenced by the presence or absence of a caring environment characterised by the presence of humanistic values (F1), authentic (F2) and trustful (F4) relationships, and the creation of spaces that foster mutual support (F8) and respect the person's dignity even when they require assistance with the most basic human needs (F9). Finally, where the two general indicators are concerned, the patients' self-assessment of their general health situation was positively impacted by the cultivation of sensitivity to self and others (F3), which is conducive to the development of an entirely different view of one's condition.

In contrast, the patients' perception of their general QoL was positively influenced by assistance with basic human needs (F9). This finding reinforces the above-discussed results that evidence a close relationship between patient perception of physical condition and their general QoL. Because of their condition, the physical dimension plays a key role in the QoL of HD patients and seeing how, as mentioned above, assistance with basic human needs is the main factor supporting their perception of their health condition, this factor also plays an important role in their perception of their general QoL.

\section{Limitations}

Our study presents a number of limitations. First, our analyses were based on a convenience sample that was not representative of the entire population of Swiss HD patients. Therefore, the results of this study cannot be generalized.
Second, our cross-sectional design provided a description at a given point in time only. Repeated measures would afford a more detailed representation of the relationships between the variables considered. Third, we used a nonspecific instrument to measure patient QoL. The use of two instruments, one specific and one not, as recommended by Danquah. Meininger, Zimmerman, Bergstrom, and Diamond, ${ }^{[46]}$ would have provided a more detailed picture of this element. Fourth, the EIIP-70 ${ }^{[28]}$ has been used in the past primarily to examine nurse perceptions of caring. Our use of it to examine patient perceptions of caring severely limits our ability to compare our results with those of other studies or to generalize them.

\section{Conclusions}

Our study shows a clear connection between the quality of NPR and patient QoL in the context of HD. Moreover, our results support the idea that an NPR based on Watson's theory of human caring ${ }^{[20,21]}$ has a beneficial effect on patient QoL. This is in line with previous research (see Cossette et al., ${ }^{[28]}$ for a review) and provides further empirical evidence in support of Watson's model. More specifically, we observed that all the dimensions of patient QoL, including environmental QoL, are affected by the quality of NPR. In particular, respect for individual dignity when assistance with the most basic human needs is required (F9) appears crucial to HD patient QoL. HD patients spend a large part of their week in the common area of the HD unit, where privacy can be hard to come by. Unsurprisingly, then, HD patients consider respect for their dignity as a key determinant of their QoL.

These findings speak to the need for continuing professional development activities to support nurses' efforts to develop and maintain a humanistic approach to caring. As HD requires nurses to have a mastery of extremely technical skills, they run the risk of focusing their attention on these and of neglecting the person attached to the machine. A purely technical approach is tempting as it does not require nurses to become personally engaged. It is easier to manage a machine than a relationship. However, in the long run, such an approach leads to a dehumanizing practice, a trend that is being observed more and more frequently in this era of evolving healthcare systems. ${ }^{[47]}$ In this context, supporting humanistic relationships will be one of the main challenges of the nursing profession in the immediate future.

\section{CONFlicts of InTEREST Disclosure}

The authors declare they have no conflicts of interest. 


\section{REFERENCES}

[1] Beaglehole R, Yach D. Globalisation and the prevention and control of noncommunicable disease: The neglected chronic diseases of adults. Lancet. 2003; 362: 903-908. https : //doi .org/10.4324/ 9781315254227-12

[2] Yach D, Hawkes C, Gould CL, et al. The global burden of chronic diseases: Overcoming impediments to prevention and control. JAMA: The Journal of the American Medical Association. 2004; 291(21): 2616-2622. PMid: 15173153. https://doi.org/10.1001/jama .291 .21 .2616

[3] Wetmore JB, Collins AJ. Global challenges posed by the growth of end-stage renal disease. Renal Replacement Therapy. 2016; 2: 15. https ://doi.org/10.1186/s41100-016-0021-7

[4] Idier L, Untas A, Koleck M, et al. Assessment and effects of therapeutic patient education for patients in hemodialysis: A systematic review. International Journal of Nursing Studies. 2011; 48: 15701586. PMid: 21924423. https://doi.org/10.1016/j.ijnurs tu.2011.08.006

[5] Chantrel F, Lassalle M, Couchoud C, et al. Démarrage d'un traitement par dialyse chronique en urgence: Quels patients? Quelles conséquences? [Beginning of chronic dialysis treatment in the emergency unit: Which patients? What consequences?]. Bulletin épidémiologique hebdomadaire. 2010; 9: 81-86.

[6] Boini S, Bloch J, Briançon S. Surveillance de la qualité de vie des sujets atteints d'insuffisance rénale chronique terminale: Rapport qualité de vie - REIN Volet dialyse 2005 [Monitoring the quality of life of persons with terminal chronic kidney disease: Quality of life report - 2005 REIN dialysis section]. Néphrologie \& Thérapeutique. 2009; 5(Suppl 3): 177-237. https://doi.org/10.1016/ S1769-7255 (09) 74545-6

[7] Delmas P, Antonini M, Berthoud L, et al. A comparative descriptive analysis of perceived quality of caring attitudes and behaviours between haemodialysis patients and their nurses. Nursing Open. 2019; 7(2): 1-8. PMid: 32089853. https://doi.org/10.1002/nop2.4 21

[8] Delmas P, O’Reilly L, Iglesias K, et al. Feasibility, acceptability and preliminary effects of educational intervention to strengthen humanistic practice among hemodialysis nurses in the Canton of Vaud, Switzerland: A pilot study. International Journal for Human Caring. 2016; 20(1): 31-43. https://doi.org/10.20467/1091-5 $710-20.1 .31$

[9] De Santo NG, Perna A, El Matri A, et al. Survival is not enough. Journal of Renal Nutrition, 2012; 22(1): 211-219. PMid: 22200445. https://doi.org/10.1053/j.jrn.2011.10.010

[10] Kopple JD, Kim JC, Shapiro BB, et al. Factors affecting daily physical activity and physical performance in maintenance dialysis patients. Journal of Renal Nutrition: The Official Journal of the Council on Renal Nutrition of the National Kidney Foundation. 2015; 25(2): 217-222. PMid: 25701942. https://doi.org/10.1053/j.jrn. 2014.10.017

[11] Almutary H, Bonner A, Douglas C. Symptom burden in chronic kidney disease: A review of recent literature. Journal of Renal Care. 2013; 39(3): 140-150. PMid: 23826803. https://doi.org/10.1 $111 / \mathrm{j} .1755-6686.2013 .12022 \cdot \mathrm{x}$

[12] Mollaoglu M. Depression and health-related quality of life in hemodialysis patients. Dialysis \& Transplantation. 2004; 33(9): 544555 .

[13] Tsai YC, Hung CC, Hwang SJ, et al. Quality of life predicts risks of end-stage renal disease and mortality in patients with chronic kidney disease. Nephrology, Dialysis, Transplantation. 2010; 25: 1621-1626. PMid: 20037172. https://doi.org/10.1093/ndt/gfp671
[14] Lovink MH, Kars MC, de Man-van Ginkel JM, et al. Patients' experiences of safety during haemodialysis treatment - a qualitative study. Journal of Advanced Nursing. 2015; 71(10): 2374-2383. PMid: 26013601. https://doi.org/10.1111/jan. 12690

[15] Shahgholian N, Yousefi H. Supporting hemodialysis patients: A phenomenological study. Iranian Journal of Nursing and Midwifery Research. 2015; 20: 626-633. PMid: 26457103. https ://doi.or $\mathrm{g} / 10.4103 / 1735-9066.164514$

[16] Bennett PN. Technological intimacy in haemodialysis nursing. Nursing Inquiry. 2011; 18: 247-252. PMid: 21790875. https://doi. org/10.1111/j.1440-1800.2011.00537.x

[17] Boykin A, Schoenhofer S, Valentine K. Health care system transformation for nursing and health care leaders: Implementing a culture of caring. New York, NY: Springer; 2013. https : //doi .org/10 $.1891 / 9780826196446$

[18] Swanson KM. What is known about caring in nursing science: A literary meta-analysis. In A. S. Hinshaw, S. L. Feetham, \& J. L. F. Shaver (Eds.), Handbook of clinical nursing research. Thousand Oaks, CA: Sage; 1999. 31-60 p. PMid: 10563461. https: //doi.org/10.4135/9781412991452.n3

[19] Swanson KM. What is known about caring in nursing science: A literary meta-analysis. In M. C. Smith, M. C. Turkel, \& Z. R. Wolf (Eds.), Caring in nursing classics: An essential resource. New York, NY: Springer Publishing; 2013. 59-102 p. https ://doi.org/10 $.1891 / 9780826171122.0004$

[20] Watson J. Nursing: The philosophy and science of caring (rev. ed.). Boulder, CO: University Press of Colorado; 2008.

[21] Watson J. Human caring science: A theory of caring science (2nd ed.). Sudbury, ON: Jones \& Bartlett; 2012.

[22] Watson J. Postmodern nursing and beyond. Toronto, ON: Churchill Livingstone; 1999.

[23] Cara C. Managers' subjugation and empowerment of caring practices: A relational caring inquiry with staff nurses (Unpublished doctoral dissertation). University of Colorado, Boulder, CO; 1997.

[24] Desmond ME, Horn S, Keith K, et al. Incorporating caring theory into personal and professional nursing practice to improve perception of care. International Journal for Human Caring. 2014; 18(1): 35-44. https://doi.org/10.20467/1091-5710-18.1.35

[25] Wei H, Fazzone PA, Sitzman KL, et al. The current intervention studies based on Watson's theory of human caring: A systematic review. International Journal for Human Caring. 2019; 23: 4-22. https://doi.org/10.20467/1091-5710.23.1.4

[26] Gray J, Grove S, Sutherland S. Burns and Grove's The practice of nursing research: Appraisal, synthesis, and generation of evidence (8th ed.). Philadelphia, PA: Elsevier - Health Sciences Division; 2017.

[27] Cossette S, Cara C, Ricard N, et al. Assessing nurse-patient interactions from a caring perspective: Report of the development and preliminary psychometric testing of the Caring Nurse-Patient Interactions Scale. International Journal of Nursing Studies. 2005; 42 : 673-686. PMid: 15982465. https://doi.org/10.1016/j.ijnu rstu.2004.10.004

[28] Cossette S, Pepin J, Fontaine G. Caring Nurse-Patient Interactions Scale. In K. L. Sitzman, \& J. Watson (Eds.), Assessing and measuring caring in nursing and health sciences. New York, NY: Springer; 2019. 251-270. https://doi .org/10.1891/9780826195425.0022

[29] Watson J. Nursing: The philosophy and science of caring. Boulder, CO: University Press of Colorado; 1985.

[30] Watson J. Human science and human care: A theory of nursing (2nd printing). New York, NY: National League for Nursing; 1988.

[31] Kalender N, Tosun N, Çınar FI, et al. Assessing the attitudes and behaviors of nursing students according to Caring Nurse-Patient 
Interaction scale. Gulhane Medical Journal. 2016; 58(3): 277-281. https://doi.org/10.5455/Gülhane.181127

[32] Yilmaz D, Çinar HG. Examination of attitudes of nursing department senior students towards caring nurse-patient interaction. Journal of Human Sciences. 2017; 14: 3300-3309. https ://doi .org/10.1 4687/jhs.v14i4.4911

[33] Leplège A, Réveillère C, Ecosse E, et al. Psychometric properties of a new instrument for evaluating quality of life, the WHOQOL-26, in a population of patients with neuromuscular diseases [Article in French]. Encephale. 2000; 26(5): 13-22.

[34] WHOQOL Group. Development of the World Health Organisation WHOQOL-BREF Quality of Life Assessment. Psychological Medicine. 1998; 28: 551-558. PMid: 9626712. https://doi.org/ 10.1017/S0033291798006667

[35] R Core Team R: A language and environment for statistical computing. Vienna, Austria: R Foundation for Statistical Computing; 2013 Available from: http://www.R-project.org/

[36] KDIGO. KDIGO clinical practice guideline for the management of blood pressure in chronic kidney disease. Kidney International Supplements. 2012; 2(5).

[37] Calong KC, Soriano GP. Caring behavior and patient satisfaction: Merging for satisfaction. International Journal of Caring Sciences. 2018; 11(2): 697-701.

[38] Bevan M. Nursing in the dialysis unit: Technological enframing and a declining art, or an imperative for caring. Journal of Advanced Nursing. 1998; 27: 730-736. PMid: 9578202. https: //doi.org/10.1046/j.1365-2648.1998.00603.x

[39] Combras, J. Caring behavior of the staff nurses in selected hospital in Paranaque: Input to staff development program (Unpublished master's thesis). Philippine Womens University; 2011.

[40] Papastavrou E, Efstathiou G, Tsangari H, et al. A cross-cultural study of the concept of caring through behaviours: Patients' and nurses' perspectives in six different EU countries. Journal of Advanced Nursing, 2012; 68: 1026-1037. PMid: 21834834. https : //doi.org/10.1111/j.1365-2648.2011.05807.x

[41] Zoni S, Verga ME, Hauschild M, et al. Patient perspectives on nurseled consultations within a pilot structured transition program for young adults moving from an academic tertiary setting to communitybased type 1 diabetes care. Journal of Pediatric Nursing. 2018; 38 : 99-105. PMid: 29357987. https://doi.org/10.1016/j.pedn .2017 .11 .015

[42] Bernstein M. Identity politics. Annual Review of Sociology. 2005; 31: 47-74. https://doi.org/10.1146/annurev.soc.29.010 202.100054

[43] Sheikhzadegan A, Nollert M. Religion, the public sphere, and identity politics: How a radical Muslim organization defies the populist right in Switzerland. European Societies. 2017; 19(5): 645-669. https://doi.org/10.1080/14616696.2017.1334951

[44] Kammerer J, Garry G, Hartigan M, et al. Adherence in patients on dialysis: Strategies for success. Nephrology Nursing Journal: Journal of the American Nephrology Nurses' Association. 2007; 34(5): 479-486.

[45] Delmas P, Cohen C, Loiselle MC, et al. Symptoms and quality of life from patients undergoing hemodialysis in Switzerland. Clinical Nursing Studies. 2018; 6(2): 63-72. https ://doi.org/10.5430/ cns. v6n2p63

[46] Danquah FVN, Meininger J, Zimmerman L, et al. Frequency, severity and distress of dialysis-related symptoms reported by patients on hemodialysis. Nephrology Nursing Journal. 2010; 37: 627-638.

[47] Adams LY, Maykut CA. Bullying: The antithesis of caring acknowledging the dark side of the nursing profession. International Journal of Caring Sciences. 2015; 8(3): 765-773. https : //doi .org/10.2 0467/1091-5710.23.1.1 